\title{
FPR NO. 1, AN EXPERIMENT IN STANDARD IZED AND PREFABRICATED LAW
}

\author{
REED DICKERSON*
}

70 DEAL fairly, fully, and at the same time understandably, with the gigantic problems of a government agency set up to regulate a major phase of the national economy, it is often necessary to go beyond orthodox legal techniques. This is especially true of an agency like the Office of Price Administration which is faced with regulatory problems of a kind and degree that have never before been faced. These are problems that are likely to persist wherever the government attempts to deal directly and comprehensively with the every-day activities of the market place.

Governmental regulation of business is nothing new; but never before has government dealt with an economy so complicated. Intricate regulations are likewise well known; but never before has government attempted to apply controls so involved and fast-changing directly to day-to-day business operations. Federal tax regulations, involving only periodic study and then mostly by lawyers, can be arranged and presented in traditional legal form, but complex orders like those establishing pricing methods for the 2,500 fruit and vegetable canners or the 550,000 grocers, which must be referred to continually and usually without benefit of counsel, call for methods of presentation that are better adapted to the needs of laymen.

The Office of Price Administration has dealt directly with this problem by attempting to issue regulations that are not only adequate "Iegally" but written for the non-lawyer. Progress has been made in simplifying style and in achieving greater clarity through the use of such devices as explanatory material and examples. Of equal importance, frontal attacks are continuing on the fundamental problems of structural organization. These have been sufficiently successful to promise solution of some of the regulatory problems that will probably accompany any further extension of direct governmental control over specific commercial operations.

A good example of these attacks is the story of how one major problem of "legal engineering" was dealt with in the FoodLegal Branch of the Office of Price Administration. Basically, this involved the problem of how to coordinate a vast amount of regulatory material applicable to a line of

* Associate Division Counsel and Consultant on Agricultural Commodities, Office of Price Administration, Washington, D.C. 
grocery products without sacrificing the specialized treatment necessary to handling problems peculiar to individual commodities. The legal device developed for this purpose has not only done the job it was supposed to do but may serve as a model for the solution of similar problems elsewhere. Because it is essentially new in character and directly affects the operations of both government and the persons who are subject to regulation, it is believed that a brief explanation of the scheme may prove useful.

\section{WHAT THE PROBLEM WAS}

After the issuance of the General Maximum Price Regulation ${ }^{\mathrm{I}}$ in April, I942, it became necessary to write a number of separate commodity regulations establishing maximum prices for many seasonal processed dry grocery products. This had to be done quickly. Regulations were written for canned vegetables (Maximum Price Regulation I $_{52}$ ), ${ }^{2}$ soups (MPR I8I), ${ }^{3}$ jams and jellies (MPR 226), ${ }^{4}$ dried fruits (MPR 227), ${ }^{5}$ apple butter (MPR 232), ${ }^{6}$ apple products (MPR 233), ${ }^{7}$ dried prunes and raisins (MPR $242),{ }^{8}$ pitted and macerated dates (MPR 243 ), ${ }^{9}$ and miscellaneous products (MPR 262). ${ }^{10}$ The commodity groupings were largely accidental; the order in which the regulations were issued depended mainly on the order in which the raw agricultural materials were harvested and processed. Commodities and commodity problems were dealt with as they arose, on a piecemeal basis. In other sections of the Office of Price Administration, the situation was frequently the same.

What impressed us most during I 942 was not so much the common problems shared by the various industries as the diversities among them. Each regulation tended to be written principally with the draftsman's eyes fixed on the commodity classification before him. There were, of course, common problems to be dealt with, many of which remained partially submerged until later in the year, but it was impossible to attain more than a bare minimum of uniformity beyond a few "boilerplate" provisions.

${ }^{2} 9$ Fed. Reg. 1385 (I944). (Only the most recent Federal Register compilations are cited in this discussion. For present purposes, later amendments are not important.)

The General Maximum Price Regulation "froze" the prices of most commodities (at all levels of production and distribution) at the highest prices the particular seller charged during March, I942. Although a necessary temporary expedient, it produced abnormal prices for most seasonal commodities. In addition, it squeezed distributors wherever their March selling prices reflected purchases made earlier at prices lower than the costs of replacement frozen in March.

${ }_{7}^{2}$ Fed. Reg. 3895 (1942).

38 Fed. Reg. 2998 (1943).

4 Ibid., at $298 \mathrm{r}$.

$s_{7}$ Fed. Reg. 753I (I942).

68 Fed. Reg. 2985 (I943).

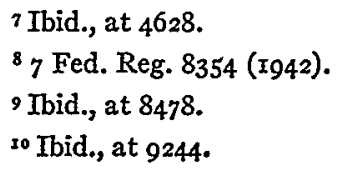


Among these were the prohibition clause ("don't charge more than ceiling prices"), the evasion clause ("don't evade the regulation"), the discounts and allowances clause ("continue your customary discounts"), the recordkeeping clause ("keep making and preserving your usual records"), and several others that developed early and naturally. (A time-pressed draftsman is always grateful to find a usable paragraph he can borrow from an earlier regulation.)

Today it is easy to criticize the results of this piecemeal program. Yet it was a program required by the necessity of speed and comprehensive action. Mature development and full coordination had to bide their time.

When inventory was taken of the regulations covering the 1942 packs of these seasonal commodities, it was found that several things called for improvement. Common problems were receiving a diversity of treatment which, even where it did not raise questions of discrimination, created confusion both in the industry and within OPA itself. For instance, under MPR I 52, a man who was a "canner" because he processed canned corn was also a "canner" of canned peas he handled only as a distributor, whereas under MPR 207 a man who processed frozen corn was a "primary distributor" of frozen peas he handled in that way. Under MPR I85, a cooperative canner "borrowed" a ceiling price from his closest non-cooperative competitor; under MPR 207, a cooperative freezer "borrowed" only a raw material cost increase. And so on. These were minor discrepancies but they needed correction.

Secondly, there seemed to be (at least on the surface) too many regulations. Why have one regulation on canned fruits, another on canned apple products, another on apple butter, another on jams and jellies? The greater the number of regulations, the more frequently common problems must be dealt with and the greater the repetition and the risk of unintended discrimination. In addition, the more regulations there are to be amended whenever a standardized provision is being changed, the more amendments there are to be written, typed, cleared, printed, and distributed. In a large-volume war agency, where amendments are a daily, almost hourly, occurrence, this means a serious loss of time.

In 1943 a higher degree of standardization was achieved. In the writing of regulations for the I943 packs, it was possible to select from the 1942 regulations those provisions that seemed to have worked best. However, even then adequate standardization was not immediately attainable because what worked adequately for the early-pack commodities often required improvement for later commodities. The development of the provisions covering "primary distributors" is a good example. This problem 
was first dealt with, somewhat crudely, in MPR 326 (macaroni products). ${ }^{\text {II }}$ Generally similar provisions were later included in MPRs 335 (peanut products), ${ }^{12} 427$ (processed beans), ${ }^{13}$ and 428 (cider vinegar). ${ }^{14}$ However, mature treatment of the problem was not achieved until Amendment I2 to MPR 306 (canned fruits and vegetables), ${ }^{\mathrm{x}}$ and the pricing technique adopted in that amendment was further refined in later regulations like MPR 462 (prepared flour mixes). ${ }^{16}$

The important thing is that, although a satisfactory treatment of the primary distributor problem was finally developed, time was too short to permit cleaning up the inadequacies of the earlier regulations. New regulations had to be written, and in a hurry. These included not only regulations covering the I943 packs of products for which special regulations had been written in 1942 but regulations like those named in the preceding paragraph covering commodities that had previously remained under the General Maximum Price Regulation.

However, the year 1943 permitted a more forthright approach in some areas to the problems of the diversity and multiplicity of regulations.

The answer to both problems seemed to be the same: consolidation. By combining regulations, one can automatically standardize and, of course, reduce the total number of regulations to be serviced. One modest example was MPR $306,{ }^{17}$ which combined canned fruits and canned vegetables of the I943 pack and certain related canned products like canned mushrooms, sauerkraut, etc. Before, the canner of fruits and vegetables dealt with two or more regulations; now he dealt with one.

A more pretentious attempt at consolidation was MPR $426,{ }^{18}$ which applies generally to fresh fruits and vegetables. This regulation brought together a large number of fresh fruits and vegetables that were diverse enough to be handled under different pricing methods, but shared a large enough number of common problems to warrant making them bedfellows. Common provisions (general explanation, prohibition clause, definitions of terms like "pool car," "carlot sale," "wholesale receiving point," "freight," etc.) were set up in the body of the regulation itself. Specific pricing provisions, however, were set forth in a number of appendices, where commodities were grouped for pricing purposes. For example, Ap-

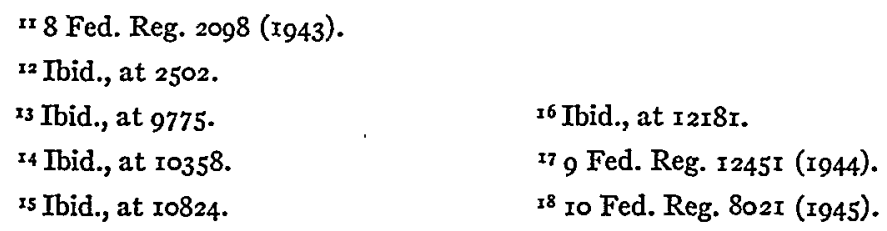


pendix $\mathrm{G}$ was devoted to apples, Appendix $\mathrm{H}$ to miscellaneous winter vegetables, Appendix I to citrus fruits, and so on.

In the administration of these attempts to simplify and consolidate, OPA learned certain fundamental principles of organization. One of these is that physical consolidation does not necessarily mean greater workability and comprehensibility. Consolidation solves some of the problems of standardization but it creates new and equally difficult ones. For one thing, differences in pricing methods cannot always be successfully reconciled within the compass of a single instrument without causing confusion. For example, in some instances dollars-and-cents pricing and formula, pricing require basic approaches that cannot be stated in a single integrated regulation without needless difficulty. This was particularly true of MPR 306, which combined dollars-and-cents prices and "freeze" prices for canned fruits and vegetables of the 1943 pack. $^{x 9}$

The establishment of maximum prices for a large number of processed dry groceries involves a multiplicity of pricing methods; which must be adapted to the various commodities. This multiplicity does not become greater when separate pricing methods are stated in separate documents nor is it lessened when a single document is used. The hard fact is that these diversities inhere in price control and no amount of "simplification" can reduce them below a certain minimum. Moreover, there is no virtue in collecting in a single document pricing methods addressed to diverse groups of sellers that have nothing in common. An industry devoted primarily to canned fruits and vegetables, for example, would be unnecessarily annoyed by a regulation encumbered with pricing schedules on tobacco and beer. In short, one document is not always simpler than two. On the contrary, it was found advisable to issue three separate regulations covering wholesale and retail sales of dry groceries, instead of one or even two.

This, then, was the dilemma. On the one hand, the Food Price Division was tempted to write a separate price regulation for each group of food commodities requiring individual treatment or made by a different industry. On the other, the Division was under pressure to emphasize the recurring problems' and lump otherwise divergent pricing methods into common regulations. Nor were the difficulties lightened by frequent insistence that the Division go both directions at once!

Yet it did just that.

${ }^{29}$ A dollars-and-cents provision specifically names the maximum prices applicable to the commodity. A "freeze" pricing method states that the maximum prices for the commodity are to be determined separately by each seller on the basis of the prices he charged during a named base period (e.g., "the first 60 days after the beginning of the r94I pack"). 


\section{MEETING THE PROBLEM}

Food Products Regulation No. $\mathrm{I}^{20}$ and its family of supplements represents an attempt to resolve the fundamental dilemma existing in some fields between the wish for consolidation and the necessity of treating different problems differently.

In this case, the conflict was resolved by combining the best features of both approaches and minimizing their limitations. To accomplish this, each regulation considered for membership in the plan was divided into two parts: (I) "boilerplate" provisions and (2) provisions peculiar to the commodity group. The recurring provisions were segregated, standardized and stated in a single autonomous pricing document, issued as Food Products Regulation No. I. The nonrecurring provisions were stated separately from the master regulation and separately from each other according to their natural groupings. Each of these separate documents was issued as a "supplement" to the master regulation. ${ }^{2 x}$ Thus, Supplement $\mathrm{I}^{22}$ covers macaroni products; Supplement $6,{ }^{23}$ frozen fruits and vegetables; Supplement $7_{2}^{24}$ canned fruits and vegetables; Supplement $9,{ }^{25}$ dried fruits; and so forth. In this way, the common provisions were dealt with as a unit, while the individual pricing methods were handled on an individual basis.

This approach somewhat resembles that of the "appendix" type of regulation, which in its main body contains the common-denominator provisions and in its appendices lists the pricing tables or methods that need to be kept functionally apart. However, the appendix type of regulation has technical limitations that often become acute when a large number of complicated pricing methods is involved. For one thing, appendices are legally part of the regulation and therefore cannot be frequently amended without causing confusion. (Amendments have to be numbered consecutively and cannot be grouped according to the appendices or basic provisions to which they are applicable.) Moreover, it is ordinarily necessary to amend the main body of the regulation whenever a commodity is added to or withdrawn from an appendix. Likewise, the addition or deletion of an appendix itself normally involves a similar adjustment in the main body of the regulation. The larger the number of appendices and the com-

${ }^{20} 9$ Fed. Reg. 67II (x944).

2x It was suggested that the individual pricing documents be called "adopting regulations," but the term "supplement" was less novel and better suggested the family-of-regulations idea, with stronger emphasis on the master regulation.
${ }^{22} 9$ Fed. Reg. 6720 (I944).
24 Io Fed. Reg. I750 (I945).
23 Tbid., at 8057.
${ }_{25} 9$ Fed. Reg. Ir794 (I944). 
modities covered by them, the more complicated the problem of integrating the regulation, including the maintenance of an intricate system of headings and cross references that contribute to administrative inflexibility. For all these reasons, it was believed important to keep the supplements to FPR I, as well as the master document, completely autonomous documents in order to maintain the highest degree of flexibility. Appendix $\mathrm{K}$ is a part of MPR 426 , but Supplement 7 is not part of FPR ${ }^{26}{ }^{26}$

The second important feature of FPR $\mathrm{r}$ is the manner in which its substantive provisions are respectively combined with those of its supplements to form, in each case, a working whole.

In gathering into a single document the provisions most commonly used in price regulations for processed dry groceries, consolidation of the largest possible number of recurring provisions for the largest possible number of commodities was the goal. This, again, involved a dilemma. If only provisions applicable to all commodities had been included, the master regulation could have covered only a small number of commodities. Conversely, if under these conditions inclusion of a wide group of commodities had been sought, the number of recurring provisions would have been too small to justify segregation. Frequency charts were therefore constructed showing the extent to which various types of provisions being used recurred in the regulations being considered for consolidation. The inclusion in FPR I of a number of provisions for which these charts showed large, although not universal, applicability greatly enlarged its usefulness. This meant, of course, that some of the "boilerplate"provisions did not apply to some of the supplements.

It was because of this difficulty that a unique feature of FPR I was adopted. Instead of making it apply to a number of "supplements," which are incorporated by reference and which in turn spell out exceptions to forestall the application of inappropriate provisions, the normal order of incorporation by reference was reversed. Thus, FPR I has force only to the extent that its terms have been incorporated by its supplements. Taken by itself, the regulation names no prices, applies to no one and, in fact, has no legal force whatsoever! It lives only to the extent that supplements breathe life into its provisions by specifically adopting them. It is this use of inverted and selective incorporation by reference that gives the regulation its great flexibility. Many or few supplements can adopt all or part of its provisions, even in varying combinations, without the need of a single amendment to the master document itself.

${ }^{26}$ The appendix type of regulation, of course, remains in many cases a useful device for presenting generally uniform pricing methods using a substantial amount of tabular material. 
The toleration in FPR I of a certain amount of surplusage, that is, "boilerplate" provisions of less than roo per cent applicability, created no greater disadvantage than is already met in many regulations of the "appendix" type, where experience has shown the frequent necessity of including a clause to the effect that "if any special provision is contrary to or inconsistent with any general provision, the special provision shall be controlling. ${ }^{27}$ FPR I frankly recognizes the normal impossibility of writing any comprehensive document of too per cent applicability without making such exceptions. Troublesome questions of the applicability of the general provisions to specific situations are largely avoided because each supplement forthrightly states which general provisions are applicable and (by necessary implication) which are not.

To summarize, the essential plan of Food Products Regulation No. I and its family of supplements is built upon three basic principles:

(I) The basic regulation, as distinct from its supplements, is an autonomous document, printed and administered separately from its supplements.

(2) Each supplement, in addition to being separate from the basic regulation, is an autonomous document, printed and administered separately from other supplements.

(3) The basic regulation applies to a given group of commodities only to the extent that the applicable supplement expressly adopts its provisions.

With these three points in mind let us examine the documents themselves.

\section{FPR I IN ACTION}

The master regulation consists of an "Explanation" and 46 sections. The Explanation gives a short account of the general scheme and indicates that the reader is to get his bearings from the applicable supplement. Article I includes $\mathrm{I}_{4}$ sections, each giving a definition of some general term, like "processor," "primary distributor," or "customary receiving point." Article II includes I6 sections, each a separate pricing provision of a general nature. Selecting at random, section 2.2 gives a method for converting a price for a product in tin to a price for the same product in glass; Section 2.II gives the rules for payment of brokers; Section 2.I5 covers units of sale and fractions of a cent; and so on. Article III covers miscellaneous boilerplate provisions not affecting maximum prices. Thus, section 3.6 names certain records the seller must keep; section 3.9 explains the effects of transferring a business or stock in trade.

${ }^{27}$ See, for example, Section I(d) of MPR 426 and Section I34I.55I(c) and (d) of MPR 306. 
Taken by itself, Food Products Regulation No. I is hardly stimulating reading. Except for the explanatory material at the beginning, and the general grouping of the sections into three articles, the regulation is a singularly disjointed affair. But FPR $I$ is not a document to be read by itself. It gives only the missing pieces in the puzzle. Functionally, the seller does not begin with the master regulation. He starts with the particular supplement that applies to him. Both documents are slanted accordingly.

Here is how it works in practice. A processor makes certain macerated date products. He gets copies of FPR I and Supplement $4 .{ }^{28}$ Supplement 4 (like all the other supplements) starts off in Article I by telling him (I) what products it applies to, (2) what sellers it applies to, (3) where it applies, (4) what regulation it supersedes, and (5) when it is effective. In a standardized section 2, it next tells him to remember that some of the provisions of FPR I have been made a part of the regulation and that these provisions are listed later in the supplement. Section 3 defines the terms "pitted domestic dates," "macerated domestic dates," and "domestic date products," and concludes with a list of the words defined in FPR I that apply to Supplement 4.

Article II, which in every supplement is devoted to pricing methods, consists of a section naming specific dollars and cents maximum prices for sales by processors and distributors other than wholesalers and retailers, followed by a section listing those pricing provisions in Article II of FPR I that apply to this supplement.

Article III covers miscellaneous provisions. For this supplement no special miscellaneous provisions were needed, so that Article III contains only a section that lists the applicable miscellaneous provisions of FPR I.

Altogether, Supplement 4 covers barely more than one page. It tells the processor almost all he needs to know for his day-to-day operations. It also tells him what kind of applicable material is to be found in FPR ${ }^{29}$ Thus, instead of dealing with a much longer document largely containing material that is of only occasional interest, the processor works with a more usable regulation..$^{30}$

${ }^{28} 9$ Fed. Reg. 6726 (I944).

29 It might have been easier to list in the supplement those sections of FPR I that were not adopted, but in that case the reader would have had to make unnecessary trips to FPR I to find out what provisions did apply. It was also felt that the supplement would be more usable if a separate list (instead of one over-all list) were used in each article at the place where questions of applicability would arise.

${ }^{30}$ The supplements vary in length, naturally. All but four are three pages or less. Supplement 6 (frozen fruits and vegetables) is about seven pages long; Supplements 7 and 13 (canned fruits and vegetables), which use a highly complex pricing method, about thirty-seven, and fifty, respectively; Supplement I5 (jams and jellies), nine. 
If he adds certain canned apple products to his line, the processor obtains Supplement Io; ${ }^{3 x}$ if he adds packaged breakfast cereals, he obtains Supplement $I x .^{32}$ He tailors the regulation to his own needs and avoids dealing with regulations covering commodity groups in which he has no interest.

Occasionally, reference will have to be made to FPR I itself, but no matter how many supplements he is dealing with, he will find in FPR I a document that provides the same standardized provisions for all supplements.

\section{SOME TECHNICAL PROBLEMS}

There were times during the preparation of FPR I when it was felt that this was an impossible technical job. The basic idea behind the plan was simple enough, but making the pieces fit, without producing a result even more unwieldy than the original regulations, was a complicated problem, indeed.

Needless to say, a prodigious drafting job was involved in drawing standardized provisions so general and flexible that they could be used in almost all existing and future supplements, and yet specific enough that when they were incorporated in a supplement both documents adequately dovetailed.

The primary interest was to insure the greatest possible flexibility in adding, revoking, or changing particular supplements without changing the master regulation itself. To make it a completely passive or "neutral" regulation, a general title ("General Pricing Provisions for Certain Food Products (Group I)") was used, the supplements were referred to only through the abstract term "applicable supplement," and a carefully chosen list of generic terms was used throughout. For example, section I.4 defines "repacker" as "a person, other than a processor, wholesaler, or retailer, who purchases the particular goods being priced and resells them after repackaging." Note particularly the terms "processor" and "particular goods being priced." Nowhere does FPR I, or any supplement, refer to a "canner," "freezer," "dehydrator," "briner," "preserver." Instead, the broader term "processor" is used throughout the entire system, including the supplements themselves. The specificmeaning of "processed" in each supplement is implied by the definition of the commodity itself. Also, FPR I refers to no specific commodity. It refers generally to the "product being priced" or "item being priced." This has caused no uncer-

${ }^{3 x} 9$ Fed. Reg. 1485 I (1944).

${ }^{32}$ Io Fed. Reg. 2614 (1944). 
tainty, because in practice the reader always has a particular commodity in mind as he reads the regulation.

Although the applicability of any section of FPR I depends on its incorporation into a supplement, the job of integrating the two documents in each case was complicated by the frequent necessity of providing in the supplement more than one type of pricing method or to price more than one kind of seller. Some standardized provisions are meant to apply to all sellers when incorporated in a supplement, whereas other sections are applicable to particular kinds only. The problem of restricted applicability could have been handled in each supplement at the place where the section is incorporated, but this would have complicated what was intended to remain a simple list of adopted sections. Instead, the beginning of each standardized pricing provision states what kind of seller it applies to when incorporated, and in some cases also what kind of pricing method it applies to.

For example, section 2.x, which permits a processor with two seasonal packs of a food product to figure prices separately for each pack, begins with the sentence, "This section applies only to processors." Section 2.2, providing for container type and size conversions, begins, "This section applies to processors and repackers," True, some of the supplements do not involve problems of repackers, but two extra words are slight payment for over-all clarity.

Section 2.6 tells the seller when he must figure a delivered price. It begins, "When this section applies to a supplement, it applies to all sellers covered by the supplement. However, it applies only to maximum prices based on sales which the seller made during a base period named in the supplement." It then goes on to state the pricing rules. This section, of course, would be adopted only by a supplement that used a "freeze" 33 method of setting ceiling prices. If such a supplement also established dollars-and-cents maximum prices, the draftsman would want to make it clear that the adopted section applied to "freeze" but not to dollars-andcents ceiling prices. In addition to the desirability of keeping the supplement's list of incorporated provisions unencumbered, it is wise to spell out subtleties of this type in the incorporated section itself in order to make the master regulation as foolproof as possible in the hands of hurried or unsophisticated draftsmen preparing later supplements.

The paragraph quoted from section 2.6 also illustrates how another troublesome problem was dealt with. In a number of boilerplate sections, it was possible to standardize all but one or two minor parts. For example,

${ }^{33}$ Op. cit. supra, note $x$. 
the base periods used in "freeze" pricing methods vary widely. Instead of attempting to spell out specific base periods, section 2.6 simply refers to the "base period named in the applicable supplement." Thus, at the place where Supplement 2 (macaroni products) ${ }^{34}$ lists section 2.6 of the master regulation as applicable, it adds, "The base period is March I942." Similarly, section 2.9, which provides standardized pricing methods for primary distributors, limits their markups to the "markup named in the applicable supplement." Supplement 7 , in adopting this provision, provides, "The maximum markup is $8 \%$." 35

\section{HOW THE PLAN HAS WORKED OUT}

Food Products Regulation No. I was issued on June I6, I944. Since then there has been ample opportunity to test it. It appears to have been successful.

By and large, it has justified the claims made for it in the Statement of Considerations. Briefly, it has provided " the most flexible possible method of simultaneously dealing with similar problems similarly and different problems differently." Together with its supplements, it has greatly reduced "the total number of provisions under which the various industries covered by the plan are now operating." It has provided "the automatic standardization of all basic provisions included." This has helped to unify and coordinate OPA pricing techniques, keep each supplement automatically abreast of improvements in the basic provisions, and facilitate general compliance with the basic provisions. It has greatly reduced the time heretofore necessary to change any provision of general applicability.

In addition, it has facilitated the drafting of new regulations (supplements). FPR I provides the draftsman with 46 prefabricated provisions, and the existing supplements give him a ready-made general pattern into which he can fit the pricing provisions peculiar to the given commodity group. It also serves as a check-list to guard against the danger of forgetting important provisions of general applicability. This not only improves internal governmental efficiency but directly benefits the affected industry as well as the consuming public, if for no other reason than that it saves time.

Just how much time and paper have been saved is a matter for speculation. After more than a year there are sixteen supplements in operation.

\footnotetext{
${ }^{34} 9$ Fed. Reg. 6722 (1944).

${ }^{35} \mathrm{~A}$ minor additional point: the master regulation was given an effective date mainly because the amendments to it, which serve as amendments to the supplements, require effective dates.
} 
Each supplement is four to ten pages shorter than it would have been if it had been combined with the master regulation. To that extent they are more manageable. The master regulation itself has been amended only twice, but the important thing is that for each change the job had to be done once instead of sixteen times.

There is, however, one apparently vulnerable spot in the regulation. Objections have been raised against the necessity of having to refer to two documents for any given commodity: the master regulation and the applicable supplement. It is now believed that not only has this criticism been met but that this aspect of the plan has been turned into an advantage by drawing off less-used provisions into the master regulation and thus facilitating the day-to-day use of the supplements.

It is not generally understood that, so far as ease of understanding is concerned, the number of legal "documents" is irrelevant. The fact that OPA issued 202 maximum price regulations in I 943 has no bearing upon the simplicity and usability of these regulations. Even a single "regulation" may consist of many unattached pieces of paper. For instance, immediately before the compilation of MPR 426 following Amendment 57, there were at least forty-five different pieces of paper to be dealt with (the Amendment 12 compilation and subsequent amendments). ${ }^{36}$ On the other hand, it is sometimes a disadvantage to integrate several documents. For example, if you handle only fresh vegetables, you will be interested in Appendix $H$ of MPR 426 , but you will not have much concern with the thirty-three pages that go to make up Appendices $I ; J$, and $\mathrm{K}$.

The real problem is not to have few or many regulations, or few or many separate sheets of paper, but to set up a well-ordered arrangement and to keep the burden of cross-references and surplusage to an absolute minimum. It is like planning a kitchen: you want to place each item so as to reduce the total number of steps as much as possible. In other words, the

${ }^{36}$ It is impossible for a government agency that must act fairly and quickly in a complicated economic field, where regulations are necessarily intricate, to avoid the frequent issuance of amendments. This is especially true of the Office of Price Administration, as it is required to operate under the Emergency Price Control Act. At any given time, therefore, a maximum price regulation is likely to consist of at least several pieces of paper. Because of the delay and expense involved, it has not been feasible to reprint the entire regulation in its amended form each time a change is made. (Several regulations have required a hundred or more amendments.) Therefore, compilations can be made only periodically. The longer the regulation, the longer it takes to issue a compilation (a minimum of several weeks is involved). If, in addition, amendments are currently being issued on an almost weekly basis, it becomes difficult to compile a long regulation at all (e.g., MPR 426). This is a source of frequent confusion or irritation. FPR I offers a substantial advantage in this respect. The basic regulation and the separate supplements, being autonomous documents, can be compiled separately and thus with much greater facility. 
drafting job is satisfactory if it calls for the least possible page-turning. The real problem, then, was one of understandability and "findability," and not of how many separate "documents" were issued or whether pages were physically attached or not.

Instead of increasing the number of "documents," FPR I reduced it by including all relevant provisions of 'other miscellaneous documents that had theretofore affected the sellers involved. Thus, it includes certain definitions from the Emergency Price Control Act and General Maximum Price Regulation that before had usually been incorporated by reference and a number of supplementary orders that were not normally incorporated and therefore occasionally served as a trap for the unwary. Because of this, and the fact that the plan facilitates compilation, there has been a net reduction also in the number of separate pieces of paper that must be handled by the reader.

As added precautions, the following steps were taken:

I.) The master regulation and the supplements were arranged so that they paralleled each other in general arrangement of subject matter.

2.) Large section numbers (to catch the eye) were used in the offset copies of the master regulation that were circulated to the public.

3.) To avoid possible confusion between the section numbers of the master regulation and those of the supplements, a decimal system of numbers was used in the master regulation (e.g., section I.I, section I.2) and ordinary whole numbers in the supplements.

4.) Throughout, many features of style simplification and clear presentation were adopted. Presentation in a straightforward, economical style was supplemented at appropriate places with explanatory material and examples, as well as with helpful typographical devices of paragraphing, headings, and italics. ${ }^{37}$

In more than a year of use, it has been gratifying to see that the complexities of execution and draftsmanship did not result in complexities of operation and use. FPR I and its supplements have proved themselves, on the whole, an effective and smoothly working system.

WHERE DO WE GO FROM HERE?

What does the plan of FPR I offer outside the field of processed dry groceries?

So far, four other master regulations (for grains and feeds) have been

37 The prevention of "gobbledygook," or "legal fruit cake," in OPA regulations is a separate story. Credit is due such simplifiers as David Cavers and Rudolph Flesch for the strides OPA has been making toward a clearer presentation of regulatory materials. 
set up on similar lines. They suggest that the situation for which this plan is suited may recur in other fields and that adaptation of the FPR I technique may offer a possible solution to some common organizational drafting problems.

At an early stage in the development of FPR $I$, the Denver Regional Office of the Office of Price Administration adopted the scheme for its retail community food pricing orders. The master order was called "Basic Community Pricing Order No. B-r, ${ }^{38}$ and individual schedules of prices were issued as separate orders "adopting" the general provisions of the basic order. This plan has recently been put on a national basis. As explained in the applicable Statement of Considerations, "In the administration of the national community dollars-and-cents ceiling price program, District and Regional Offices were required to issue orders of local applicability. In most cases, separate orders were required for separate phases of the program, because of the nature of the commodities covered by the phase and the frequency of price changes. It has been observed that many provisions of these local orders are or can be made identical. It has therefore been possible to segregate and standardize the provisions which are common to the greatest number of local community pricing orders issued under Revised General Order, No 5 '. These provisions are issued as "Food Products Regulation No. 4." The particular pricing orders are referred to as "adopting orders" in the master regulation.

Food Products Regulation No. $4,^{39}$ therefore, has extended the original plan and made it a means of coordinating the work of the national, regional and district offices in a field where many provisions can and should be standardized, while others must be given individual and localized treatment..$^{\circ}$ This means great savings in time, paper, printing, and distribution labor, because the individual adopting orders involving perishables are issued weekly or monthly for distribution to all retailers, while the basic order needs to be distributed only once.

How many additional uses there may be for the plan of FPR $I$, in similar or varied form, can hardly be anticipated at this time. However, the general expansion of government activities suggests that the idea may well be worth exploitation in fields other than that of price control.

${ }^{38}$ On file with the Federal Register.

39 10 Fed. Reg. 4 I03 (1945).

$4^{\circ}$ Under FPR I, each supplement is issued by the national office and covers one group of commodities in all areas. Under FPR 4, each "adopting order" is issued by a regional or district office and applies to all commodities covered by that plan, but in the particular area only. 